\title{
Modelling of Multi Layer Feed forward Neural Networks to Determine the Compressive Strength of Marmara Region Aggregate's Concrete
}

\author{
Okan Özbakır*, Erkin Nasuf \\ Mining Engineering, Mining Faculty, Istanbul Technical University, Turkey
}

Copyright $(2016$ by authors, all rights reserved. Authors agree that this article remains permanently open access under the terms of the Creative Commons Attribution License 4.0 International License

\begin{abstract}
We aim to estimate concrete compressive strength by using the physical properties of the aggregates that are the main components of concrete. For this aim, concrete samples were prepared with aggregates having different origins and characteristics obtained from different 10 locations of the Marmara region. The compressive strength's results obtained by changing the aggregates were compared by ensuring the other components forming the concrete remained constant. 330 separate experiments were conducted to determine the physical characteristics of the aggregates, and these characteristics were used as input data in a multi layer Feed Forward Network model. The compressive strength of 7 and 28 days of the concrete obtained from the experiments were used as output in to a Multi-layer Feed Forward model. The training and test results from the models coincided closely with experimental results; also, the results were compared to the estimations made with a linear regression method.
\end{abstract}

Keywords Aggregate, Multi Layer Feed Forward Neural Network, Compressive Strength

\section{Introduction}

The reason that the values of concrete's compressive strength are based building designs is that compressive loads are very important. It is only possible to determine the effect of the physical and mechanical characteristics of aggregate to the concrete's compressive strength with experiments. Such studies take a long time and are not economical. Therefore, the different estimation methods are formed using past empirical studies in order to determine the concrete compressive strength.

Artificial neural networks (ANN) are frequently used to determine concrete's physical and mechanical characteristics. Lai and Serra (1997) estimated the compressive strength over 28 days of different mixtures of concrete with an ANN model. In the study, they obtained values of the compressive strength in varied learning rates, in various network neurons and they determined that the results were very close to each other [1]. Mukherjee and Biswas (1997) developed an ANN model that is five neurons in each layer, with two hidden layers by using the perception network and back propagation algorithms in order to estimate the mechanical behaviour of the concrete at high temperature [2]. They estimated the stretching transformation relationship of the material at high temperature and obtained the results that were similar to experimental results. Yeh (1998) used the values of day, fine aggregate, course aggregate, super plasticizer, water, fly ash, and cement as data in an adaptive ANN model in order to estimate the compressive strength of concrete [3]. Hong-Guang and Ji-Zong (2000) estimated the compressive strength by using a multi layer perceptron ANN; they used quantity of the chemical additive, slump, aggregate/cement, sand/aggregate, fineness module, the greatest dimension of aggregate, cement, water, water, cement and type of cement as input data into the model [4].

Dias and Pooliyadda (2001) formed an ANN and multi regression model in order to estimate the compressive strength and slump rate of concrete and compared the results to $r^{2}$ (coefficient of multiple correlation) statistical values. They determined in their study that $r^{2}$ values in the ANN models were better than $r^{2}$ values found with the multi regression models [5]. Akkurt et al. (2003) developed a model to estimate the compressive strength of cement mortar with ANN and showed that it would be able estimate the compressive strength of the cement mortars and the very small rates of error with ANN model [6]. Lee (2003) formed models by using multi neural networks and single neural networks in order to estimate the compressive strength in the different hours and days by using ANN; they determined that the experimental results and their results obtained from the models were compatible [7]. Baykasoglu et al.(2004) estimated the compressive strength of cement mortar of 28 days by using genetic programming techniques and regression analysis methods and observed that the best result was from values obtained from an ANN model in 
comparison with $\mathrm{r}^{2}$ statistical values [8]. Ince (2004) formed an ANN model concrete with the back propagation in order to estimate the ANN model fracturing parameters. In his model, he separated 22 pieces of 40 different data collected from literature for training and also 18 pieces for testing. The results found from the experimental studies were compared to their results from the ANN model [9]. Öztaş et al.(2006) evaluated the performance of two hidden layered ANN models according to RMS, $\mathrm{r}^{2}$ and MAPE statistical values in order to estimate the compressive strength and slump values of the high quality concretes and showed in his studies that the compressive strength and slump values would be able to be estimated by ANN [10]. Raheman and Modani (2013) used a back-propagation ANN model and estimated SCC compressive strength with the very small errors [11]. Hoła and Schabowicz (2005) verified the correlation between test results and neural results of concrete compression strength from 24 to $105 \mathrm{MPa}$ after 28 days of curing period. They compared results taken from the practical studies and the results from the neural model [12].

In general, studies have tried to estimate concrete's resistance by using the rates of components forming the concrete. In this study concrete compressive strength have been searched to calculate by using the physical properties of the aggregate.

\section{Multi Layer Feed Forward Network and ANN}

The Multi-layer feed forward network (MLFFN) is a type of artificial neural network which moves the information forward from the input layer, through the hidden layer to the output layer. Artificial Neural Network is an information processing system designed and developed on the basis of human brain and its neural system. The Multi-layer Feed Forward network contains large numbers of neurons that are connected to each other. The artificial neuron, which is the key component of neural networks, has dendrite and axone connections like the biological neuron, as shown in Figure 1. The information coming to the neuron from the neighboring neurons reaches the neuron through dendrites. The neuron output is calculated considering the weight coefficients of the connected dendrites, and the activation function of the neuron is transferred to the neighboring neurons through an axone. Each neuron in a layer connected to the neurons in the next layer. The information learned from the networks is kept by means of the weight coefficient of the dendrites [13].

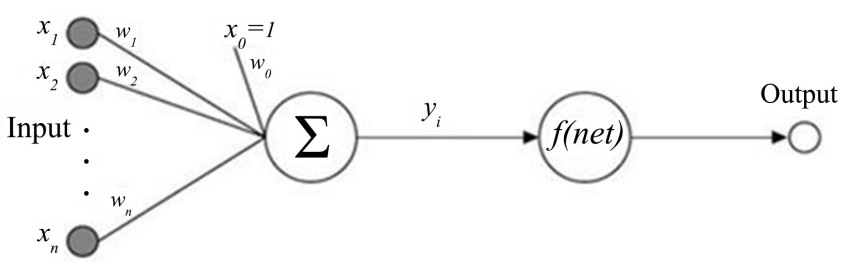

Figure 1. Mathematical model of neuron

The artificial neuron is a model that imitates the data processing system of a biological neuron mathematically [14]. The input-output equity of neurons within a mathematical model and activation function is given in Figure 1.

Network consists of layers of computational units and connects each other in a feed-forward way (Figure 2.). There are no cycles or loops in the network.

The physical properties of the aggregate were used in the input layer as $\left(x_{\mathrm{i}}\right)$, and the compressive strength of the concrete of 7 and 28 days were used in the output layer in the model developed with Multi layer feed forward network (Eqn. 1).

$$
y_{i}=f\left(\sum_{j=1}^{m} w_{i j} x_{j}+b_{i}\right)
$$

Hidden layers were used between both layers in order to increase the model's learning capacity. The activation function was taken as the sigmoid function (Eqn. 2).

$$
f(n e t)=\frac{1}{1+e^{-n e t}}
$$

The back-propagation learning algorithm was used in the training of the Multi layer feed forward network [14]. The compressive strength value was calculated by the model by using the entry parameter values and the available network parameters of the artificial neural networks (weight coefficients and biases). The input parameter values at any stage of the training process were compared to its real value. Firstly, the connection coefficients between the hidden layer and the exit layer were updated in order to decrease the error found; then, the connection coefficients between the hidden layer and the input layer were updated. The output was recalculated for the entry parameters found in the network entrance by using the updated weight coefficients. This process was continued until the difference between the original output parameter observed by the result of experiments and the network output will decrease under the error's value determined previously. This learning algorithm is called a back propagation algorithm, as the line followed in updating of the network parameters is from output towards input [15].

One of the most important parameters affecting the network's learning performance in the back propagation algorithm is the learning coefficient [15]. In this case, the learning coefficient is very large as it is mentioned that the algorithm is attached to the local optimums. It is probable that there is any decrease in the learning performance, although a serious increase is observed in the learning speed.

Otherwise, in case the learning coefficient is very small, as any decrease in the network's learning performance is mentioned, the learning process takes a very long time [16]. Therefore, determining an optimum value for the learning coefficient is a very important matter in the back propagation algorithm.

In this study, the back propagation algorithm with adaptive learning coefficient, where the learning coefficient was determined adaptively, was used in order to eliminate the disadvantages arising out of both matters mentioned above. The momentum coefficient was selected as 0,90 . 


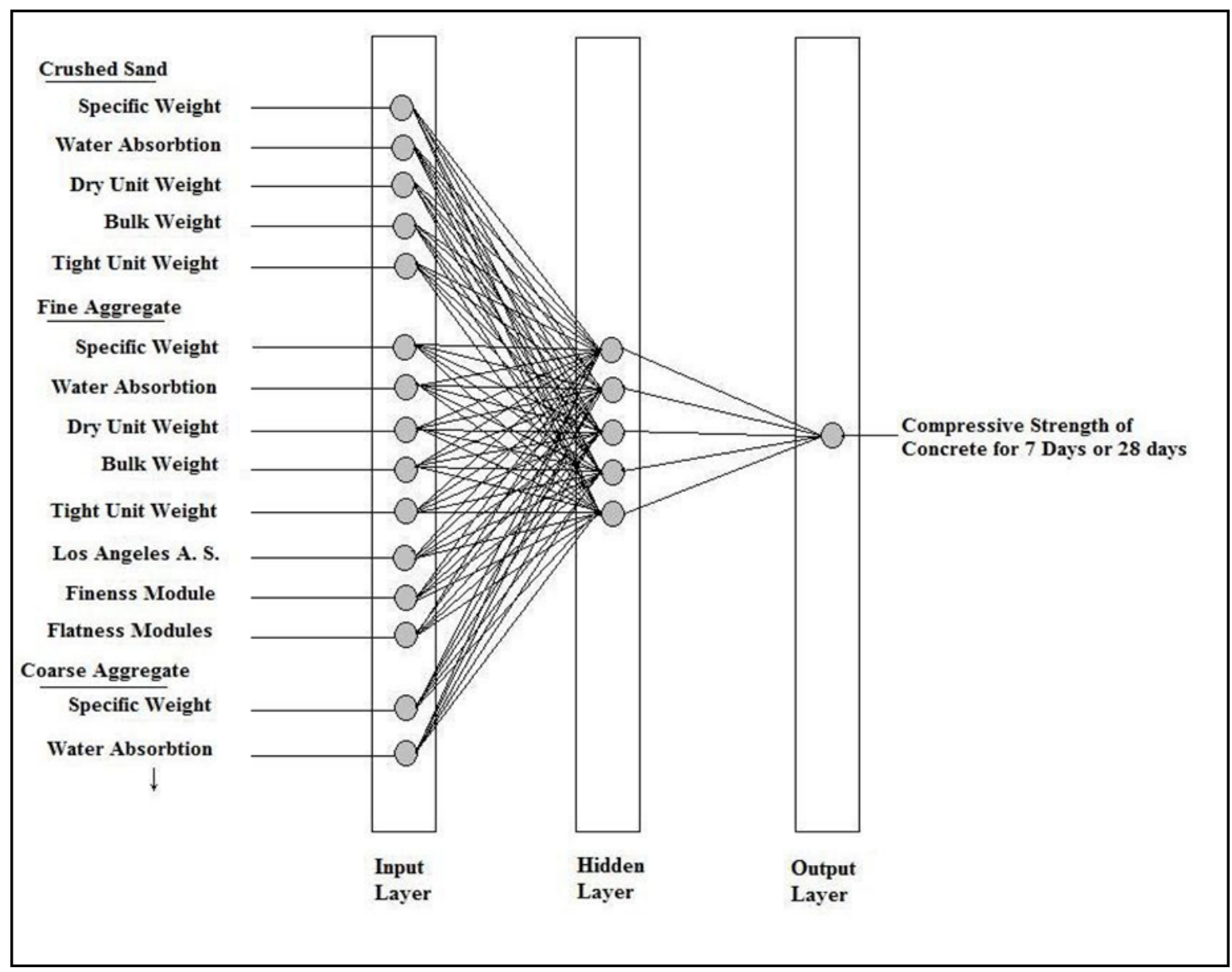

Figure 2. Multi layer feed forward network structure for predicting the compressive strength [17].

\section{Experimental Studies and Data Preparation}

The aggregates used in the production of concrete were basically assured from 10 different aggregate pits. Their physical characteristics were separately based in modelling by separating each sample of aggregates into three classes of dimensions in conformity with the concrete's production standard.

The physical and mechanical characteristics of the aggregate forming the concrete were represented with 20 different parameters (Table 1.).

These parameters determining the aggregate's characteristics were used as the entry parameters in the artificial neural network. Consequently, both network input layers determining the concrete resistances of 7 days and 28 days consist of 20 neurons (Table 2.).

The data obtained from the results of 330 compressive strength experiments were used in the model. In experiments, the amounts of cement, water, ash, crushed sand, plasticizer, fine aggregate, and course aggregate remained constant in weight (Table 3.). 250 pieces of 330 data in total, obtained experimentally, were separated for training; the remaining 80 data were used for testing in order to estimate the compressive strength with the network [17].
As there is only the concrete strength as the output parameter in the exit of network, in both Multi layer feed forward network models there is only one neuron in the exit layer. It was observed that the hidden layered network model with five neurons showed the best performance after the number of neurons in the hidden layer and the number of the hidden layer's neurons in different numbers were tried experimentally as there was not any absolute analytic rule in order to determine the number of neurons in the hidden layer; consequently, the number of neurons of the hidden layer were also determined as 5 for both models.

Its performance decreased significantly when it was operated with the test data, while the performance of model was high in the training stage; also, the performance of the network was high in the training stage when the number of neurons of the hidden layer was selected greater than 5 . The network's total square error did not decrease under a specific value when the number of neurons of the hidden layer was selected to be less than 5. Consequently, the network's learning capacity was not enough to learn the relationship between the output parameters and the input parameters used in the problem when the network's hidden layer was designed with less than 5 neurons. 
Table 1. Multi layer feed forward Network model architecture

\begin{tabular}{|c|c|c|c|c|}
\hline Data set & \multicolumn{4}{|c|}{330 Aggregate samples for Compressive Strength Test obtained from 10 different location } \\
\hline \multirow{3}{*}{ Input Parameters } & $\begin{array}{l}\text { Crushed sand } \\
\text { (KK-1) }\end{array}$ & $\begin{array}{c}\text { Specific weight, Water absorption, Dry unit weight, Bulk weight, } \\
\text { Tight unit weight }\end{array}$ & \multirow{3}{*}{$\underline{\underline{\text { Output }}} \underline{\text { Parameters }}$} & \multirow{3}{*}{$\begin{array}{l}\text { Compressive } \\
\text { strength }\end{array}$} \\
\hline & $\begin{array}{l}\text { Fine aggregate } \\
\quad(\mathrm{K}-1)\end{array}$ & $\begin{array}{l}\text { Specific weight, Water absorption, Dry unit weight, Bulk weight, } \\
\text { Tight unit weight, Fineness module, Flatness module }\end{array}$ & & \\
\hline & $\begin{array}{l}\text { Coarse aggregate } \\
(\mathrm{K}-2)\end{array}$ & $\begin{array}{l}\text { Specific weight, Water absorption, Dry unit weight, Bulk weight, } \\
\text { Tight unit weight, Los Angeles A.S., Fineness module, Flatness module }\end{array}$ & & \\
\hline $\begin{array}{l}\text { Activation } \\
\text { Function }\end{array}$ & Sigmoid Function & \multicolumn{2}{|l|}{ Number of input layer neurons } & 20 \\
\hline $\begin{array}{l}\text { Performance } \\
\text { function }\end{array}$ & MAPE & \multicolumn{2}{|l|}{ Number of hidden layer and neurons } & 1 and 5 \\
\hline Number Of layer & 3 & \multicolumn{2}{|l|}{ Number of output layer and neuron } & 1 and 1 \\
\hline
\end{tabular}

Table 2. A part of imput data set from aggregate properties

\begin{tabular}{|c|c|c|c|c|c|c|c|c|c|c|c|}
\hline Parameters & $\begin{array}{l}\text { Agg. } \\
\text { Kodes }\end{array}$ & Loc. 1 & Loc. 2 & Loc. 3 & Loc. 4 & Loc. 5 & Loc. 6 & Loc. 7 & Loc. 8 & Loc. 9 & Loc. 10 \\
\hline \multirow{3}{*}{ Specific weight $(\mathrm{gr} / \mathrm{cm} 3)$} & KK-1 & 2.70 & 2.74 & 2.68 & 2.75 & 2.64 & 2.71 & 2.77 & 2.69 & 2.66 & 2.61 \\
\hline & K-1 & 2.71 & 2.72 & 2.73 & 2.73 & 2.67 & 2.73 & 2.71 & 2.68 & 2.68 & 2.71 \\
\hline & $\mathrm{K}-2$ & 2.71 & 2.75 & 2.72 & 2.71 & 2.68 & 2.71 & 2.71 & 2.70 & 2.74 & 2.67 \\
\hline \multirow{3}{*}{$\begin{array}{c}\text { Water } \\
\text { absorption (\%) }\end{array}$} & KK-1 & 1.30 & 1.68 & 1.24 & 0.95 & 2.15 & 1.09 & 1.65 & 1.32 & 0.92 & 1.62 \\
\hline & K-1 & 0.70 & 0.41 & 0.78 & 0.48 & 0.92 & 0.32 & 0.82 & 0.53 & 0.88 & 0.52 \\
\hline & $\mathrm{K}-2$ & 0.40 & 0.28 & 0.42 & 0.36 & 1.56 & 0.19 & 0.25 & 0.26 & 0.37 & 0.27 \\
\hline \multirow{3}{*}{$\begin{array}{c}\text { Dry unit } \\
\text { weight }(\mathrm{gr} / \mathrm{cm} 3)\end{array}$} & KK-1 & 2.68 & 2.67 & 2.65 & 2.68 & 2.61 & 2.69 & 2.68 & 2.65 & 2.66 & 2.63 \\
\hline & K-1 & 2.70 & 2.68 & 2.71 & 2.69 & 2.78 & 2.73 & 2.69 & 2.68 & 2.72 & 2.75 \\
\hline & K-2 & 2.71 & 2.74 & 2.70 & 2.74 & 2.75 & 2.69 & 2.75 & 2.72 & 2.70 & 2.73 \\
\hline \multirow{3}{*}{$\begin{array}{c}\text { Bulk } \\
\text { weight }(\mathrm{gr} / \mathrm{cm} 3)\end{array}$} & KK-1 & 1.59 & 1.47 & 1.28 & 1.47 & 1.75 & 1.69 & 1.32 & 1.57 & 1.63 & 1.64 \\
\hline & $\mathrm{K}-1$ & 1.45 & 1.36 & 1.29 & 1.47 & 1.48 & 1.39 & 1.36 & 1.41 & 1.49 & 1.47 \\
\hline & K-2 & 1.44 & 1.34 & 1.41 & 1.45 & 1.43 & 1.46 & 1.51 & 1.36 & 1.39 & 1.36 \\
\hline \multirow{3}{*}{$\begin{array}{c}\text { Tight unit } \\
\text { weight }(\mathrm{gr} / \mathrm{cm} 3)\end{array}$} & KK-1 & 1.67 & 1.63 & 1.49 & 1.62 & 1.83 & 1.79 & 1.52 & 1.72 & 1.75 & 1.76 \\
\hline & K-1 & 1.71 & 1.67 & 1.53 & 1.74 & 1.75 & 1.71 & 1.61 & 1.63 & 1.76 & 1.81 \\
\hline & K-2 & 1.83 & 1.64 & 1.77 & 1.82 & 1.81 & 1.77 & 1.81 & 1.69 & 1.71 & 1.88 \\
\hline Los Angeles A.S & K-2 & 21.70 & 21.70 & 19.70 & 18.20 & 26.30 & 15.60 & 18.30 & 24.50 & 22.30 & 22.50 \\
\hline \multirow{2}{*}{$\begin{array}{c}\text { Fineness } \\
\text { module (\%) }\end{array}$} & K-1 & 5.55 & 4.75 & 5.68 & 5.57 & 5.75 & 5.48 & 6.15 & 5.60 & 4.95 & 5.64 \\
\hline & $\mathrm{K}-2$ & 6.82 & 6.79 & 6.59 & 6.81 & 6.20 & 6.72 & 6.79 & 7.08 & 6.28 & 6.42 \\
\hline \multirow{2}{*}{$\begin{array}{c}\text { Flatness } \\
\text { module (\%) }\end{array}$} & K-1 & 14.00 & 11.00 & 12.00 & 16.00 & 15.00 & 13.00 & 15.00 & 14.00 & 15.00 & 13.00 \\
\hline & $\mathrm{K}-2$ & 12.00 & 10.00 & 9.00 & 14.00 & 11.00 & 13.00 & 16.00 & 14.00 & 12.00 & 9.00 \\
\hline
\end{tabular}

Table 3. Weighted Distribution of Concrete Construction Materials [16]

\begin{tabular}{|c|c|}
\hline Material & Quantity $\left(\mathrm{kg} / \mathrm{m}^{3}\right)$ \\
\hline Cement & $260-275 \mathrm{~kg}$ \\
\hline Water & $185-195 \mathrm{Kg}$ \\
\hline Ash & $67-72 \mathrm{Kg}$ \\
\hline River Sand & $565-573 \mathrm{Kg}$ \\
\hline Crushed Sand & $200-210 \mathrm{Kg}$ \\
\hline I No fine Agregate & $550-565 \mathrm{Kg}$ \\
\hline II. No coarse Agregate & $485-490 \mathrm{Kg}$ \\
\hline Additive (Plasticizer) & $2,7 \mathrm{Kg}$ \\
\hline
\end{tabular}

\section{Results and Evaluations}

The results obtained from the network model and linear regression and experimental studies are given in Table 4 . The correlation coefficient between the results of the network and experimental studies for 7 days is 0,717 ; for 28 days, the correlation coefficient is 0,926 . This shows that the results of multi layer Feed Forward Network (MLFFN) are close to the result of the experimental studies.

The correlation coefficient and mean absolute percent error are used to control the performance of the neural network approach in predicting the compressive strength.The results of the compressive strengths for 7 days, 
which were obtained from the multi layer Feed Forward Network model, represent the actual values with an average of $96,2 \%$. The values of the compressive strengths for 28 days had been forecasted with $2,8 \%$ error value in the multi layer Feed Forward Network model, which means that the results had been forecasted with a $97,2 \%$ value of truth. But, the Mape values in the linear regression is more than $9 \%$ for the values of 28 days and $11,6 \%$ for the values of 7 days, as shown in Figure 3.

The multi layer Feed Forward Network results are compared with the results of experimental values; they show that multi layer Feed Forward Network results complied with experimental results with a small ratio of $2,8 \%$ mean absolute percent error. Error analysis is based on mean absolute percent error.

In the same manner, the average MAPE of the linear regression results to the results of experimental studies is $11.62 \%$.

We compared the $r^{2}$ value between the linear regression technique and results of experimental studies. This shows that for linear regression had been forecasted values of 0,479 $-0,551$ ratios but it had been seen successfully forecasted with approximately $\mathrm{R}^{2}$ values of 0,733 for 7 days and 0,740 for 28 days with the MLFFN. Comparison of experimental studies with MLFFN and LR results are given in Figure 4, 5, 6 and 7 for two different locations.

\section{Conclusions}

In this study, the estimation models were developed with the artificial neural networks as alternative approaches for determining the compressive strength of concrete produced from ten different aggregates taken from ten different regions in laboratory experiments, and the results were compared to the linear regression results.

Results obtained from experimental studies and MLFFN results were very close to each other; also, linear regression results gave worse performance.

In order to obtain better results for the learning and estimation stages of the model, it is important to include more data in the model.

As a result, experimental studies are the works, which are realized in long periods, but they are expensive, since they require more expenses and materials to be spent and more technical personnel to be employed. Thus, these losses and requirements of the experimental studies can be minimized by using of artificial neural networks models.

Artificial neural networks are inspired by biological central nervous systems of brain and are used to estimate or approximate functions that can depend on a large number of inputs and are generally unknown. ANN has the ability to implicitly detect complex nonlinear relationships between dependent and independent variables, with learning algorithm is widely used in solving various classifications and forecasting problems.

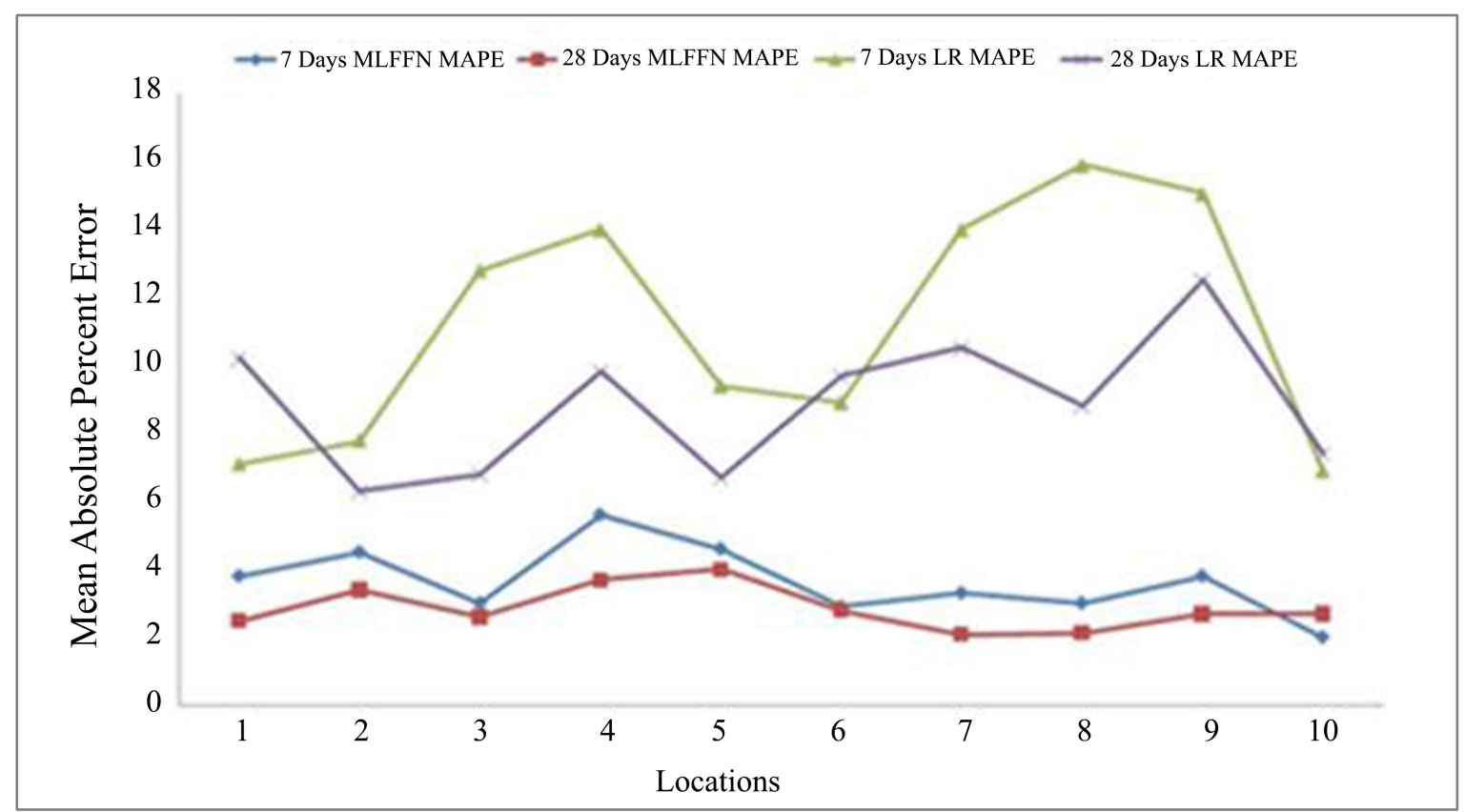

Figure 3. Mean Absolute Percent Error of ANN and LR. 
Table 4. Experimental results and output data of MLFFN and LR.

\begin{tabular}{|c|c|c|c|c|c|}
\hline \multicolumn{2}{|c|}{ Exper. Results Mpa } & \multicolumn{2}{|c|}{$\begin{array}{c}\text { MLFFN Reults } \\
\text { Mpa }\end{array}$} & \multicolumn{2}{|c|}{$\begin{array}{c}\text { Linear Reg. Results } \\
\text { Mpa } \\
\end{array}$} \\
\hline 7 days & 28 days & 7 days & 28 days & 7 days & 28 days \\
\hline 30.16 & 38.54 & 30.10 & 39.05 & 33.44 & 35.07 \\
\hline 28.48 & 38.86 & 28.71 & 40.53 & 26.76 & 41.39 \\
\hline 29.26 & 35.77 & 28.41 & 36.90 & 31.54 & 34.30 \\
\hline 29.32 & 38.52 & 28.70 & 37.20 & 29.60 & 34.05 \\
\hline 29.26 & 38.72 & 29.43 & 38.74 & 31.54 & 36.25 \\
\hline 29.36 & 38.94 & 29.21 & 38.99 & 30.64 & 39.47 \\
\hline 29.62 & 43.75 & 28.94 & 42.86 & 29.90 & 47.28 \\
\hline 28.37 & 38.44 & 28.42 & 37.76 & 25.65 & 34.75 \\
\hline 30.99 & 40.04 & 31.36 & 40.37 & 32.27 & 43.57 \\
\hline 27.85 & 35.82 & 28.82 & 37.25 & 26.13 & 39.35 \\
\hline 30.52 & 38.72 & 29.26 & 39.33 & 33.80 & 37.25 \\
\hline 29.20 & 38.56 & 29.96 & 37.65 & 26.48 & 35.09 \\
\hline 26.39 & 43.40 & 25.93 & 44.20 & 28.67 & 46.93 \\
\hline 28.86 & 38.52 & 28.57 & 38.08 & 29.14 & 37.05 \\
\hline 29.16 & 38.22 & 30.08 & 40.03 & 26.44 & 37.75 \\
\hline 27.24 & 42.35 & 25.46 & 41.14 & 29.52 & 42.88 \\
\hline 25.14 & 38.29 & 25.33 & 41.41 & 25.42 & 38.82 \\
\hline 28.76 & 39.83 & 28.72 & 38.63 & 29.04 & 42.36 \\
\hline 29.82 & 43.75 & 30.56 & 42.46 & 30.10 & 44.28 \\
\hline 30.14 & 43.88 & 30.58 & 42.05 & 35.42 & 49.41 \\
\hline 27.14 & 39.22 & 27.29 & 38.66 & 23.42 & 44.75 \\
\hline 28.94 & 38.66 & 30.18 & 38.69 & 33.22 & 33.19 \\
\hline 31.21 & 39.82 & 31.91 & 40.15 & 34.49 & 35.35 \\
\hline 28.35 & 39.04 & 28.70 & 37.55 & 26.63 & 33.57 \\
\hline 29.68 & 38.88 & 30.84 & 41.66 & 31.96 & 39.41 \\
\hline 28.82 & 42.62 & 28.09 & 44.00 & 28.10 & 46.15 \\
\hline 28.73 & 45.62 & 29.95 & 44.22 & 30.01 & 50.17 \\
\hline
\end{tabular}
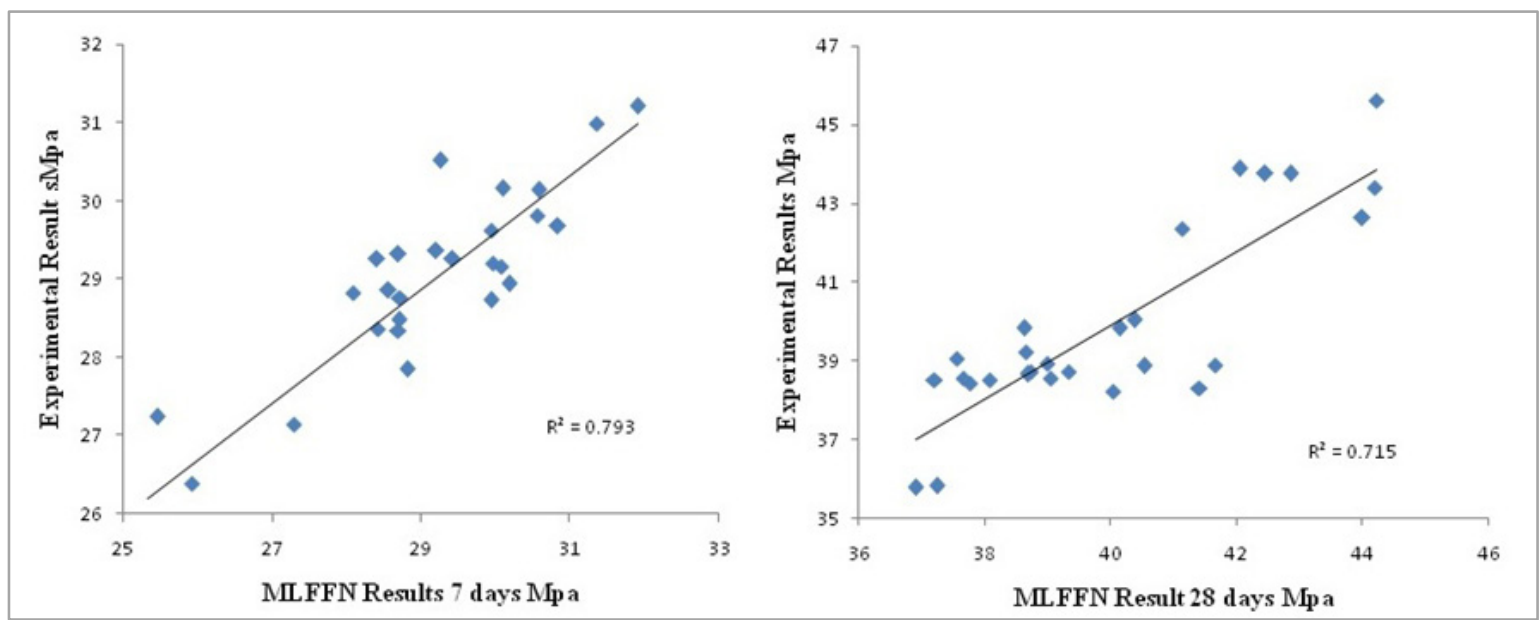

Figure 4. Comparison of the Experimental Results and the Results Obtained from MLFFN Model for location 1. 


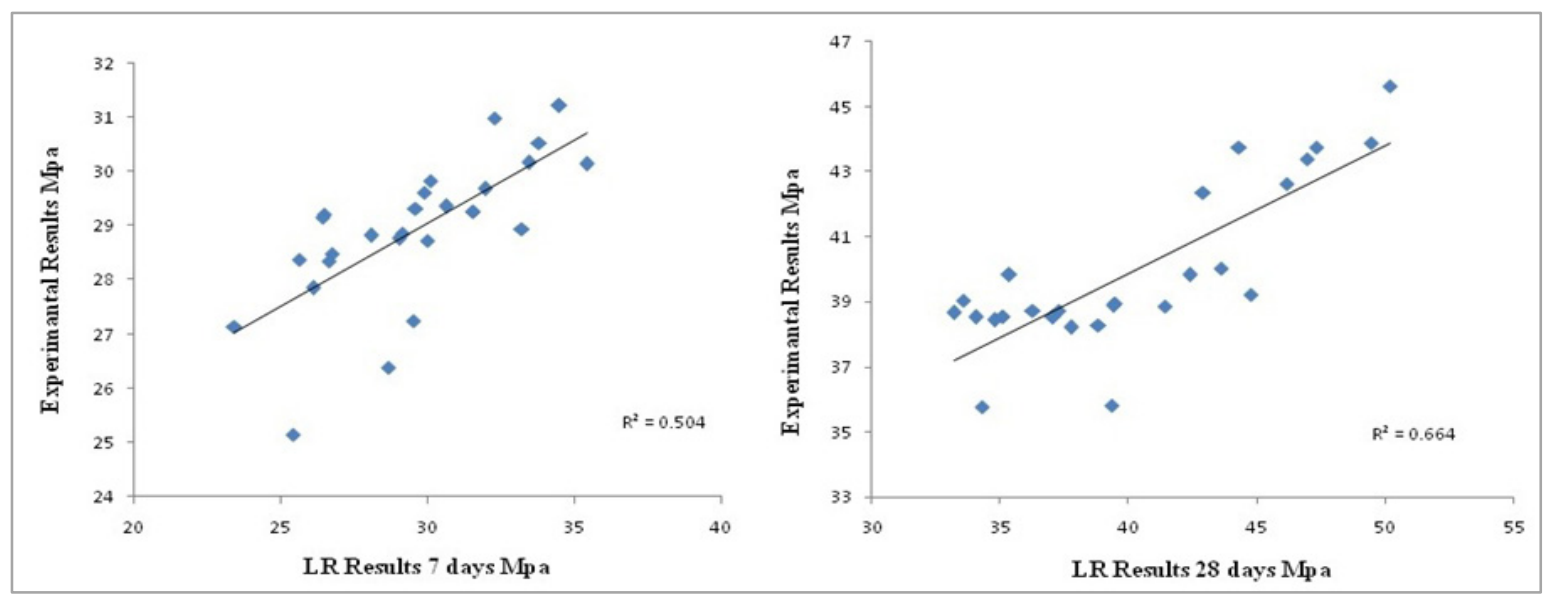

Figure 5. Comparison of the Experimental Results and the Results Obtained from LR for location 1.

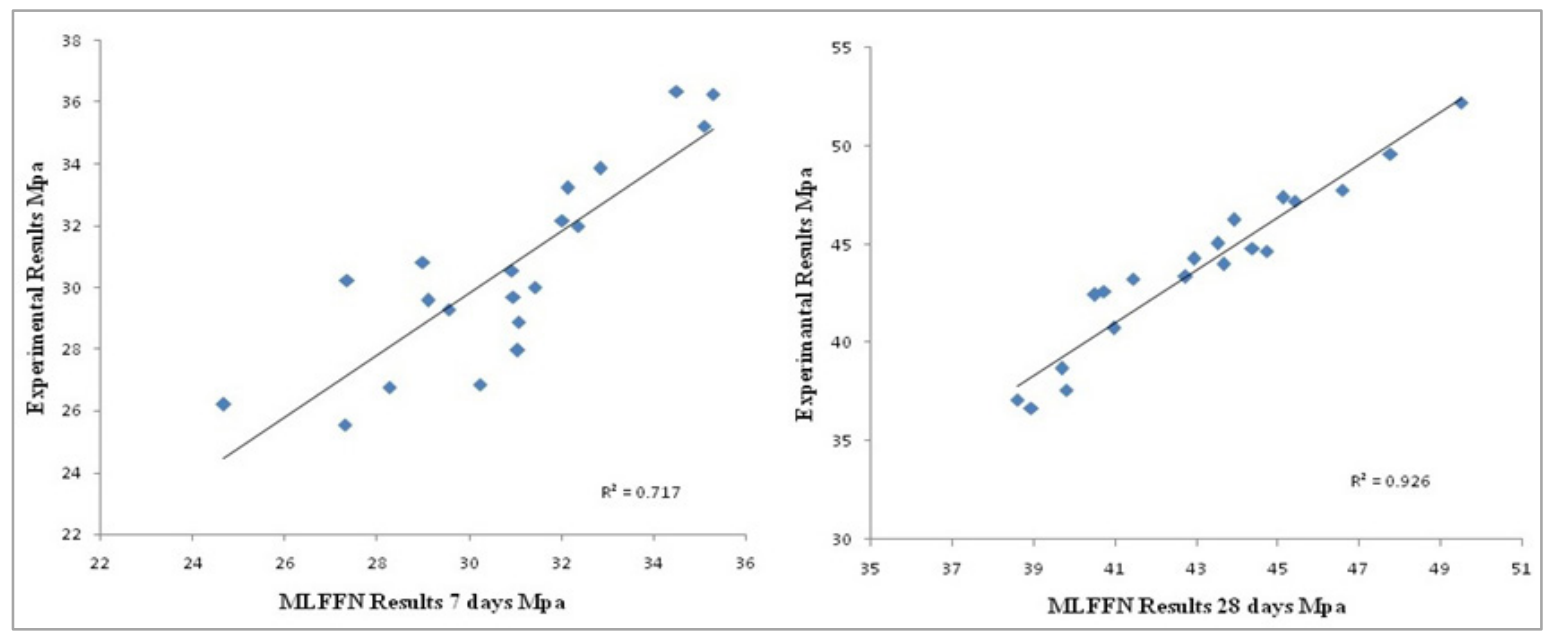

Figure 6. Comparison of the Experimental Results and the Results Obtained from MLFFN Model for location 2.
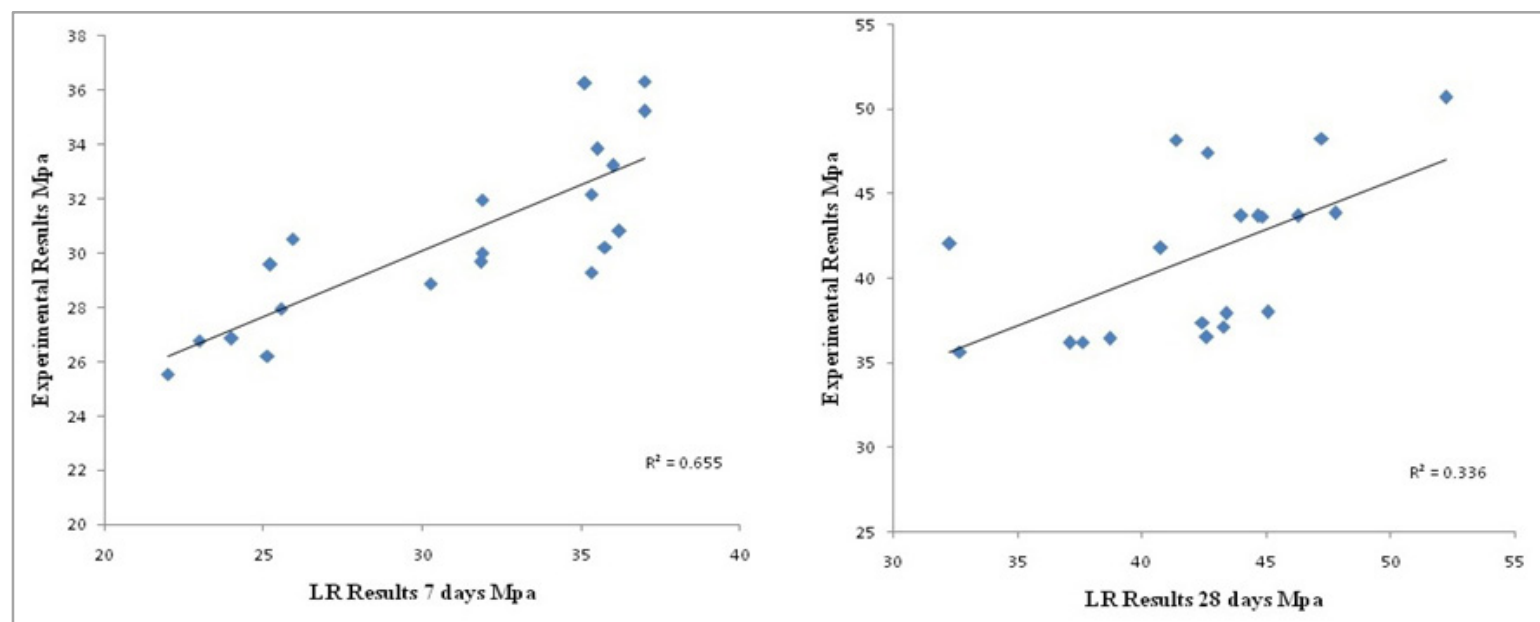

Figure 7. Comparison of the Experimental Results and the Results Obtained from LR for location 2.

93-98. . (1997).

[2] A. Mukherjee and S.N. Biswas, Artificial neural networks in prediction of mechanical behavior of concrete at high temperature, Nuclear Engineering and Design, 178(1), 1-11. (1997).

[1] S. Lai and M. Sera, Concrete strength prediction by mean of neural networks, Construction and Building Materials, 11(2),

[3] Yeh, I.C. Modeling of strength of high-performance concrete 
using ANN, Cement and Concrete Research, 28(12), 1797-1808 (1998).

[4] N. Hong-Guang, ve W. Ji-Zong, Prediction of compressive strength of concrete by neural networks, Cement and Concrete Research, 30(8), 1245-1250. (2000).

[5] W.P.S. Dias, ve S.P. Pooliyadda, Neural networks for predicting properties of concretes with admixtures, Construction and Building Materials, 15(7), 371-379. (2001).

[6] S. Akkurt, S. Ozdemir, G. Tayfur and B. Akyol, The use of GA-ANNs in the modelling of compressive strength of cement mortar, Cement and Concrete Research, 33(7), 973-979. (2003).

[7] S.-C. Lee, Prediction of concrete strength using artificial neural networks, Engineering Structures, 25(7), 849-857 (2003).

[8] A. Baykasoglu, T. Dereli and S Tanıs. Prediction of cement strength using soft computing techniques, Cement and Concrete Research, 34(11), 2083-2090. (2004).

[9] R. Ince, Prediction of fracture parameters of concrete by artificial neural networks, Engineering Fracture Mechanics, 71, 2143-2159. (2004).

[10] A. Öztas, M. Pala, E. Özbay, E. Kanca, N. Çaglar, and B. M Asghar Predicting the compressive strength and slump of high strength concrete using neural network, Construction and Building Materials, 20(9), 769-775. (2006).

[11] A. Raheman, and P.O. Modani, Prediction of properties of Self Compacting Concrete using Artificial Neural Network. International Journal of Engineering Research and Application. Vol: 13, Iss: 4 pp 333,339. (2013).

[12] J. Hoła, K. Schabowicz, Methodology of neural identification of strength of concrete, ACI Materials Journal, vol. 102, no 6, 459-464, ( 2005)

[13] W.S. Mc Culloch and W. Pitts A Locical Calculus Of The Ideas Immanent In Nervous Activity Bulletin of Mathematical Biophysics, Vol. 5, pp. 115-133. (1943).

[14] A.E. Bryson Ho Y.C. Applied optimal control, Blaisdell, New York. (1969)

[15] J.A. Hertz and R.G. Palmer Introduction to the theory of neural computation, Adisson-Wesley, New York. (1991).

[16] D.B. Parker Learning logic, MIT, no: TR-47, Cambridge (1985).

[17] O. Ozbakir, E. Nasuf and E. Bilgili Estimation of the Concrete Strength Setting off from the Physical Properties of the Aggregates by Artificial Neural Network and Linear Regression Method and Comparison of the Results, ICFCC June 3-5,2011, Iasi, Romania, pp.335-343. (2011). 